\title{
FISURAS CLASIFICATORIAS Y HIERBAS MEDICINALES. EL CASO DEL PICIETL EN LA INVENCIÓN DE LA MATERIA MÉDICA NOVOHISPANA (S. XVI)
}

\author{
Julio Ricardo Vera Castañeda \\ Universidad de Chile \\ Email: julio.vera@um.uchile.cl \\ ORCID iD: https://orcid.org/0000-0002-0076-4495
}

Recibido: 4 abril 2020; Aceptado: 16 junio 2020

Cómo citar este artículo/Citation: Vera Castañeda, Julio Ricardo (2021) "Fisuras clasificatorias y hierbas medicinales. El caso del Picietl en la invención de la Materia Médica Novohispana (s. XVI)", Asclepio, 73(1): p338. https://doi.org/10.3989/asclepio.2021.04

RESUMEN: El presente artículo estudia las representaciones escritas del picietl (tabaco) producidas en Nueva España entre 1552 y 1591. Remite al estudio de un corpus de textos médicos y el lugar que ellos destinan a la denominación y clasificación de la "materia médica" del territorio, en contextos de coexistencia de tradiciones hispanas e indígenas. Desde el caso particular del picietl, se enfatizan las dificultades que acarreó la clasificación de las hierbas del Nuevo Mundo desde el léxico del saber médico europeo y su vinculación con las estructuras simbólicas del dominio colonial. Esto se evidencia a partir de las diferentes posturas frente a la condición medicinal del humo del picietl, cuestión que manifiesta la importancia de los modos en que son usadas las hierbas dentro de la cultura médica hispana. A modo de hipótesis, se plantea que estas representaciones jugaron un rol clave en la apropiación de los saberes médicos locales, al traducir y formalizar el saber de las hierbas medicinales, que manejaban agentes indígenas claves del proceso de colonización, en el campo de conocimiento que son propios de la cristiandad occidental. Esto contribuyó a la construcción de jerarquías coloniales al fijar criterios de usos legítimos e ilegítimos de las hierbas medicinales.

PALABRAS CLAVE: Representación; Invención; Materia médica; Tabaco; México.

\section{QUALIFYING FISSURES AND MEDICAL HERBS. THE CASE OF PICIETL IN THE INVENTION OF MATERIA MEDICA IN NEW SPAIN (16 ${ }^{\text {TH }}$ CENTURY)}

ABSTRACT: This article studies the written representations of picietl (tobacco) produced in New Spain between 1552 and 1591 . It refers to the study of a corpus of medical texts and the place that they assign to the name and classification of the "medical matter" of the territory, in contexts of coexistence of Hispanic and indigenous traditions. From the particular case of picietl, the difficulties caused by the classification of New World herbs from the lexicon of European medical knowledge and their link with the symbolic structures of colonial rule are emphasized. This is evident from the different positions regarding the medicinal condition of picietl smoke, an issue that shows the importance of the ways in which herbs are used within the Hispanic medical culture. By way of hypothesis, I propose that these representations played a key role in the appropriation of local medical knowledge, by translating and formalizing the knowledge of medicinal herbs, which were managed by key indigenous agents of the colonization process, in the field of knowledge that is typical of western Christianity. This contributed to the construction of colonial hierarchies by setting criteria for legitimate and illegitimate uses of medicinal herbs.

KEY WORDS: Representation; Medical Matter; Invention; Tobacco; México. 


\section{INTRODUCCIÓN}

"Reconocer es ya un acto de conquista y sujeción" dice Antonello Gerbi en su clásico estudio La naturaleza de las Indias Nuevas (1978). Junto con identificar el eurocentrismo con que los descriptores de Indias narran y describen la naturaleza de América, el historiador italiano nos recuerda que la capacidad de clasificar y jerarquizar la naturaleza es una parte sustancial de las formas en que se ejerce el dominio. A partir de esta idea, el presente artículo analiza las representaciones del saber médico sobre el picietl (tabaco, Nicotiana tabacum L.) elaboradas en Nueva España entre 1552 y 1591. Intenta mostrar no solo cómo se desarrollan y modifican estas representaciones, sino también los mecanismos mediante los cuales se inventa e integra una parte de la "materia médica" del territorio a los marcos del saber médico de la cristiandad occidental, en coexistencia con tradiciones hispanas e indígenas.

En función de este objetivo, este escrito relee un conjunto de obras ampliamente conocidas y estudiadas, y que componen el canon de la medicina colonial novohispana del siglo XVI. Se trata de los manuscritos elaborados bajo el amparo del Colegio de Santa Cruz de Tlatelolco: el Libellus de medicinalibus indorum herbis (1552) y los "tratados médicos" que forman parte de la Historia general de las cosas de Nueva España de Bernardino de Sahagún, además de la Historia Natural de la Nueva España de Francisco Hernández, tras su expedición por el Virreinato de Nueva España en la década de 1570. También se atienden los primeros impresos médicos escritos por profesionales y puestos en circulación en la ciudad de México en el último tercio del siglo XVI: Summa y recopilación de cirugia $(1578,1595)$ del cirujano Alonso López de Hinojosos, el Tratado breve de medicina $(1579,1592)$ de fray Agustín Farfán y Problemas y secretos maravillosos de Indias de Juan de Cárdenas (1591), todos ellos vinculados con la formalización del protomédico al alero del cabildo y la instalación de la Cátedra de Medicina en 1579 en la Real Universidad de México. De manera adisional, se hace uso del Tesoro De La Lengua Castellana (1610) de Sebastián de Covarrubias, con el propósito de atender la dimensión semántica de algunos enunciados presentes en el corpus de obras sobre materia médica.

Si bien la historiografía de las ciencias de los últimos veinte años ha venido enfatizando las transformaciones del saber natural gracias a las innovaciones del conocimiento producido en y desde América, particularmente la valoración de la experiencia personal y la aproximación empírica como fundamentos del saber (Cañizares-Esguerra, 2006; Barrera Osorio 2009; Good- man, 2009; Marroquín Arredondo y Bauer, 2019), los prejuicios, creencias y expectativas del horizonte mental europeo fueron determinantes para la comprensión y las prácticas de representación del mundo natural. Resulta pertinente volver sobre la propuesta de (Edmundo O' Gorman, 2003) acerca de la Invención de América, no en un sentido llano de comprender al continente como una mera fabricación social exclusivamente europea, marginando la propia existencia del continente antes de la invasión (Nieto, 2009, p. 30) o la visión de las poblaciones indígenas que leyeron el hecho colonial bajo sus propias categorías (Navarrete, 2016) sino, más bien, en el sentido de atender el peso de la tradición cristiana occidental en la construcción de una visión colonial de la naturaleza de América, en un clima de trasformaciones de índole globalizante (Gruzinski, 2015).

Desde esta perspectiva, esta propuesta busca tensionar la idea de un traslado cohesionado y mecánico de los saberes europeos hacia América, al igual que la idea de una imposición sin fisuras de estas tradiciones. Tal como han señalado Pardo-Tomás y Sánchez Menchero, el desarrollo de la medicina hispana en la América colonial fue escurridizo y dispar, en la medida que se trató del despliegue de una "cultura médica" particular entre muchas otras que convivieron dentro de los confines del imperio hispano, pero que se caracterizó por su intención de hegemonía (2014). En esa línea, este escrito no busca la reconstrucción de un desarrollo lineal, ni muchos menos armonioso de las representaciones médicas del picietl, sino dar visibilidad a las diferentes estrategias de aquello que el saber médico europeo define como medicinal, en una sociedad donde saberes y prácticas se negocian como parte del proyecto político colonial y ese horizonte de sentido (Rappaport y Cummins, 2012).

\section{EL PROBLEMA DE LA CLASIFICACIÓN Y LA (NOCIÓN DE) NATURALEZA EN LA CRISTIANDAD OCCIDENTAL}

Antes de revisar los modos en que el picietl es enunciado como materia medicinal dentro de los manuscritos e impresos médicos del siglo XVI, es necesario discutir dos aspectos relevantes del problema de la representación de las hierbas medicinales del Nuevo Mundo. El primero de ellos tiene que ver con las prácticas clasificatorias de la cristiandad occidental de una "naturaleza" que se supone preexistente a dicha clasificación. Tal como señaló Michel Foucault en Las palabras y las cosas, las clasificaciones sólo son posibles en el lenguaje, puesto que no existe un orden presente en las cosas del mundo esperando ser revelado (2008, p.12). Por el contrario, lo que existe en el mundo es un completo desorden que subyace a cualquier lenguaje o intento de orden. En ese sentido, en las clasificaciones: 
El orden es, a la vez, lo que se da en las cosas como su ley interior, la red secreta según la cual se miran en cierta forma unas a otras, y lo que no existe a no ser a través de la reja de una mirada, de una intención, de un lenguaje: y sólo en las casillas blancas de esta cuadrícula se manifiesta en profundidad como ya estando allí, espera en silencio el momento de ser enunciado (Foucault, 2008, p. 13).

En este clásico estudio, Foucault enfatiza el rol que juega quien observa y enuncia al objeto de la clasificación como resultado del mismo procedimiento, de tal modo que cada clasificación del mundo es una experiencia histórica concreta que se entrelaza con los campos del saber, los códigos y prácticas culturales disponibles. En ese sentido el saber médico clasifica a los seres vivientes para dar cuenta de un "orden diferenciado" por medio de la "identificación" de sus "cualidades"; la diferencia entre bestias y plantas, o también entre árboles, arbustos y hierbas, y sus variables: comestibles, aromáticas o medicinales. El telón de fondo de este ejercicio es la noción de naturaleza de la cristiandad occidental que comprende, grosso modo, un dominio ajeno al de los sujetos, capaz de habilitar la distinción entre "naturaleza" y "cultura", "sociedad" o "civilización".

Al destacar que se trata de una noción de la cristiandad occidental, la "naturaleza", tal como la comprendemos, ya sea como "entorno" o "medio ambiente", forma parte de un modelo y conceptualización específica entre muchas otras posibilidades (Glacken, 1996). El llamado "giro ontológico" de la antropología contemporánea ha contribuido a este argumento al discutir el valor universal de la "naturaleza", destacando otras ontologías que anulan, revierten o movilizan (en otros sentidos) los límites discursivos del concepto, dando cuenta así de otras formas de comprender la relación entre los seres vivientes (Descola, 2012; Viveiros de Castro, 2010). Importa tomar nota de este problema al momento de analizar las representaciones del picietl, puesto que a la narrativa histórica de los estudios sobre la medicina o la ciencia novohispana le ha costado ver a la naturaleza como una categoría codificada. De hecho, las lecturas más recurrentes del corpus de textos sobre "materia médica" tienden a pasar por alto este problema discursivo, replicando el carácter eurocéntrico de estas obras al considerar la descripción de las hierbas como expresión del reconocimiento de una naturaleza preexistente (Trabulse, 1992; Pardo-Tomás y López Terrada, 1993; Fresquet y López Piñero, 1995; Bleichmar, De Vos, Huffine y Sheehan, 2009, entre otros).

Ahora bien, enfatizar la condición codificada de naturaleza no exime considerar su especificidad histórica y su rol dentro del campo de la medicina en el siglo XVI. Para Philippe Descola, nuestra comprensión moderna, heredera de las transformaciones del siglo XVI, se ha propuesto comprender la noción de naturaleza occidental como expresión de una "cosmología naturalista completamente exótica en comparación con las elecciones efectuadas por el resto de la humanidad para distribuir las entidades en el mundo y establecer en él discontinuidades y jerarquías" (2012, p.110). Como veremos a continuación, en el establecimiento de discontinuidades y jerarquías, el saber médico europeo jugó un rol fundamental, particularmente en la clasificación medicinal de la naturaleza.

\section{EL ESQUEMA HUMORAL Y LA “MATERIA MÉDICA”}

No es intención de este escrito dar una revisión a la historia del saber médico de la cristiandad occidental y su despliegue en América, pues existen varios trabajos de este tipo (Porter, 2004; Martínez Hernández, 2014). Lo que interesa poner en relieve son los esquemas, ideas y modelos textuales que acompañan la representación de las hierbas medicinales por parte de los actores del saber médico europeo. Recordemos que para el siglo XVI la medicina era la única ocupación de carácter científico que se había cristalizado en una profesión gracias al estatus intelectual que había adquirido desde su formalización universitaria en el siglo XII (Burke, 2002, p.37). Dicha condición les permitía a los médicos distinguirse de los demás "charlatanes" que ejercían la curación dentro del tejido social de la Europa de Antiguo Régimen al considerarse, a sí mismos, herederos de la doctrina desarrollada por Hipócrates en el siglo V. a. n. e., y que más tarde fue sistematizada y perfeccionada por Galeno en el siglo II. n. e. (Le Goff, 1990; Siraisi, 1990)

La tradición de Hipócrates consistía en un esquema de interpretación del cuerpo y el mundo "natural" basado en la existencia de cuatro "humores cardinales": sangre, bilis negra, flema y bilis amarilla, que a su vez se correspondían con los cuatro elementos esenciales; fuego, tierra, agua y aire. Los humores se conformaban de la combinación binaria de las cuatro cualidades primarias, de tal manera que la sangre era considerada caliente; la bilis fría y seca; la flema fría y húmeda, mientras que a la bilis amarilla se le suponía caliente y húmeda ${ }^{1}$ (Porter, 2004). Desde estas relaciones analógicas, las medicinas que se obtenían del mundo natural debían ser consideradas calientes, húmedas, frías o secas, ya que su "complexión" o "temperamento" permitía contrarrestar el trastorno que sufría el paciente (Siraisi, 1990; Martínez Hernández, 2014, Porter). En ese cuadro de posibilidades, el médico jugaba un papel central al 
descifrar la fragmentaria realidad "natural" por medio de indicios, nunca transparente. En la medida que se fue formalizando, la medicina tendió a nutrirse de otros saberes como la filosofía, la geografía, la matemática, la retórica, la física y la metafísica, cuyos dominios les permitían a los médicos afinar la atención de los signos de la naturaleza.

El esquema humoral no fue el único requisito para representar las hierbas medicinales. El saber médico europeo contaba con una tradición letrada que hacía comunicable los conocimientos sobre la salud del cuerpo humano y la naturaleza, por lo que la clasificación de las hierbas medicinales se desarrolló conforme a reglas y cánones preestablecidos por la tradición cristiano occidental (Pardo-Tomás, 2002; Morales Sarabia, 2014). La tipología más importante fue la de Materia Médica (77 d. n. e.) de Dioscórides, que desde los primeros siglos de la era cristiana fijó un formato de escritura sobre la naturaleza medicinal del orbe. A diferencia de obras predecesoras como la Historia de las plantas de Teofrasto, Dioscórides presentó una visión particularmente práctica de la naturaleza ya que, junto a la identificación y descripción de hierbas, animales y minerales, detalló las formas en que podían ser extraídas sus propiedades curativas para enfrentar trastornos y enfermedades diversas (Anderson, 1997; Morales Sarabia, 2014).

Como han señalado Reynolds, van der Geest y Hardon, la propia categoría de "materia médica" denota que las medicinas son materiales y que, en consecuencia, se inscriben dentro de los marcos sociales que habilitan o restringen su circulación entre los sujetos, al igual que las diversas objetivaciones y valoraciones que pueden tomar las materias medicinales en sus trayectos de circulación (2003, pp. 13-14) ${ }^{2}$. Desde esa perspectiva, la pregunta por las representaciones medicinales del picietl se cruza con la pregunta por su valoración, es decir, qué, cuánto y cómo de su "entidad natural" cumple con los criterios clasificatorios del saber médico europeo y de qué manera se articula la condición medicinal de la hierba, ignorando o marginando el peso cultural que poseía en sus contextos locales.

\section{EL PICIETL EN LOS MANUSCRITOS DEL COLEGIO DE SANTA CRUZ DE TLATELOLCO}

Con estos elementos que nutren al marco de comprensión de la "naturaleza" podemos pasar a atender el modo en que las obras sobre materia médica clasifican y representan al picietl. Las primeras obras por considerar son el Libellus de medicinalibus indorum herbis (1552) y los "tratados médicos" de la Historia general de las cosas de Nueva España (1577) de Bernardino de Sahagún.
Ambos manuscritos son producto de las labores del Colegio de Santa Cruz de Tlatelolco, fundado por la orden franciscana en 1536, cuyo objetivo era hacer de la elite indígena novohispana buenos cristianos y agentes de la colonización en calidad de mediadores (Laird, 2014, p. 152).

El Libellus de medicinalibus indorum herbis ha sido reconocido por la historiografía como el primer escrito científico elaborado en América (Trabulse, 1992). Se trata de un herbario elaborado apenas treinta años después de la conquista de México-Tenochtitlán y cuyo título traducido significa Opúsculo o pequeño libro de las hierbas medicinales de los indios ${ }^{3}$. Se consigna que fue compuesto en respuesta al encargo de Francisco de Mendoza, hijo del virrey Antonio de Mendoza, por Martín de la Cruz, "indio médico del Colegio de Sta. Cruz" (De la Cruz, 1996, f. 1r.) y traducido al latín por Juan Badiano, indio de Xochimilco y "profesor en el mismo Colegio" (De la Cruz, 1996, f. 63v.). En este ejercicio de traducción de saberes y formatos, el Libellus es elocuente del léxico del saber médico europeo al presentarnos al piciet/ como una de las hierbas del recetario para la diarrea:

Para aquel a quien le gruñen las tripas por diarrea, dale esta poción por clisterio auricular de hojas de tlatancuaye, corteza de quetzalilin, hojas de iztac ocoxochitl, más estas hierbas: tlanextia xiuhtontli, elozacatl, árbol tlenextia cuahuitl. Todo esto molido en agua de sabor amargo, con ceniza, un poco de miel, sal, pimienta, alectoria y, al fin, picietl (De la Cruz, 1996, f. 31v.).

El sentido práctico de esta escritura reconoce el rol medicinal del picietl sin mayores detalles, inscribiéndose junto a otras hierbas locales con sus nombres en náhuatl. Además de ayudar a la diarrea, el Libellus lo incluye en el capítulo noveno como medicina para la "Enfermedad Recurrente", ya que limpia el pus que se genera en el vientre (De la Cruz, 1996, f. 41v.). A diferencia del apartado anterior, se esbozan características de la hierba para tener cuidado: "La segunda vez se dará pasados unos cuantos días, con jugo hecho que tiene fuerza embriagante. La llamamos picietl. Se agrega sal, chile negro y chile de color claro" (De la Cruz, 1996, f. 41v.). Y también hay que considerar la variante atochietl que, en palabras de Garibay significa "Tabaco acuático cimarrón" (De la Cruz, 1996, p. 224), ilustrado y consignado en la receta para el catarro: "Quien tenga catarro o corriza, debe oler las hierbas atochietl y tzonpilihuizxihuitl, y de esta manera se aliviará el catarro" (De la Cruz, 1996, f. 15v.).

Los "tratados médicos" de la Historia general de las cosas de Nueva España (1577) de Bernardino de Saha- 
gún, también conocido como Códice Florentino, dialoga con la presentación del Libellus. Recordemos que este es el nombre del estado último del material sobre "las cosas de la Nueva España" con el que el fraile venía trabajando desde 1558, gracias a la ayuda que le proporcionaron los informantes y los ayudantes o gramáticos indígenas ${ }^{4}$. Como ha enfatizado Federico Navarrete, los "informantes" eran en su mayoría ancianos que habían vivido en tiempos previos a la conquista y que recordaban, de primera mano, las costumbres, instituciones e ideas de entonces, mientras que los "gramáticos" y otros colaboradores indígenas lo conformaban los jóvenes nobles que habían nacido un poco antes o después de la conquista y que habían sido formados en el Colegio de Santa Cruz de Tlatelolco (Navarrete, 2002, p. 100). Ellos sirvieron de intermediarios culturales entre los frailes y la sociedad indígena interpelada por el proyecto enciclopédico de Sahagún.

Bajo el modelo de la historia natural de Plinio y las enciclopedias medievales, Sahagún incluyó un completo "tratado de medicina indígena"5 (Martínez, 1981), dentro del que destaca un inventario de las hierbas medicinales del territorio con sus respectivas ilustraciones, y cuyos "informantes" son los únicos reconocidos expresamente por su nombre: Gaspar Mattías, Francisco Symon, Felipe Hernández, Miguel García, Pedro de Santiago, Miguel Damian, Pedro de Raquena y Miguel Motolinia. La descripción del piciet/ dentro de este párrafo solo se halla en la columna escrita en náhuatl, ya que el espacio destinado a la descripción en español presenta una ilustración de la hierba junto a una persona que la muele en el piso. Bajo el número veinticinco, el Códice Florentino nos dice:

Anchas, algo largas son sus hojas. Y sus flores son amarillas. Se maceran con piedras, se muelen, se mezclan con cal; con ellas se entrega el que está muy cansado y el que tiene gota. Y se mastican. Así se mastican: sólo en los labios se ponen. Emborrachan a la gente, desmayan a la gente, embriagan a la gente, y matan el hambre y ganas de comer. Al que tiene el vientre hinchado, sobre el vientre y allí, en el ombligo, se le ponen en abundancia (López Austin, 1971, pp. 145 - 147).

Siguiendo el canon de escritura, el texto señala el modo de preparación: "se maceran con piedras, se muele y se mezcla con cal", al mismo tiempo que establece una vinculación de la hierba con el cansancio y la hinchazón del vientre. Es una indicación que difiere con las del Libellus y que replica la primera relación sobre la hierba presente en el Códice Matritense, el manuscrito previo elaborado en Tlatelolco, donde se señala que el picietl "Es medicina para el cansancio. El que se fatigó la mastica. Con ella se calma. O quizás se la pone en el ombligo para curar" (López Austin, 1971, p.135).

Como bien ha señalado López Austin, la ampliación de la información entre ambos manuscritos da cuenta de los esfuerzos de Sahagún por estandarizar el conocimiento entregado por sus "informantes" indígenas. La primera versión sólo cuenta con una escueta lista de "hierbas medicinales y maderas potables", comentada por otro escribano que consignó las propiedades de las hierbas de manera irregular, mientras que la versión final de la Historia general añade indicaciones corporales específicas, estableciendo que el picietl "se mastican. Así se mastican: sólo en los labios se ponen" y también al asociar la hierba, de igual forma que el Libellus, con la condición embriagante, puesto que "Emborrachan a la gente, desmayan a la gente". Este cambio también ocurre para la descripción de la variante del picietl, el ítzyielt, que en el Matritense se menciona que es "medicina para la hinchazón" y que "La fuma el que tiene hinchado el vientre" (López Austin, 1971, p.135), mientras que la columna en náhuatl del párrafo quinto adhiere a la descripción de la hierba, señalando que "Es algo alto, delgado, derecho. Y sus hojas son como las del pícietl, verdes, vellosas, anchas. Se da en Xochimilco. Se maceran [las hojas] con piedras. Se meten en una caña para fumar; se mezclan con trementina. Se fuman" (López Austin, 1971, p. 147).

Al prestar atención al libro décimo de la Historia general, destinado a la presentación de las enfermedades y las medicinas que son propias del territorio, vemos al picietl en diversas recetas al modo en que son presentadas por el Libellus. Llama la atención que las virtudes curativas enunciadas en este apartado amplíen las presentadas en el libro XI: el picietel se enuncia mezclado con cal y en "gran cantidad" para las postemas de la cabeza6; se sugiere "oler" la hierba, sobre todo cuando está verde, para el dolor de cabeza ${ }^{7}$ y también para el romadizo ${ }^{8}$; mientras que para los quistes que salen en el cuello, la columna en náhuatl menciona que, al sacar la masilla, "enseguida se mete ahí picietl, tabaco caliento lleno de cal, lleno de sal" (López Austin, 1993, p. 75). Por su parte, la versión en español lo menciona "molido y mezclado, con la yerva llamada yietl"9. La variación de las transcripciones, tanto en náhuatl como en español, que los "gramáticos" desarrollan a partir del testimonio de los informantes, puede responder a varios motivos, desde cuestiones fortuitas hasta adiciones de último minuto. Sin embargo, destacan las escasas referencias al humo del picietl como elemento curativo, fuera de la mención en el párrafo quinto que es enunciada de manera aislada. 


\section{EL PICIETL EN LA HISTORIA NATURAL DE FRANCIS- CO HERNÁNDEZ}

El capítulo que destina Francisco Hernández al " $P$ ícietl o hierba yetl" es uno de los más extensos de su Historia natural. Doctorado en Alcalá de Henares y médico de Cámara de Felipe II, Hernández llegó a Nueva España como Protomédico general de Indias, encabezando la primera gran expedición científica en el territorio americano, con el propósito de elaborar una historia natural, labor que lo llevó a recorrer el territorio en distintas expediciones entre 1570 y 1577. Las instrucciones dadas a Hernández detallaban tratar las "cosas tocantes a la historia de las cosas naturales" y al desarrollo del oficio real del Protomédico (Hernández, 2015, p.143). Según el mandato, las fuentes del conocimiento serían los sanadores cristianos ya establecidos hacía medio siglo, pero también los indios, quienes podían entregar información sobre "las hierbas, árboles y plantas medicinales", dejando de manifiesto el foco utilitario, sanitario, económico y político del proyecto del Consejo de Indias (Pardo-Tomás, 2002, p. 144).

En cuanto al picietl, el Protomédico no solo desarrolla una exhaustiva descripción, sino también consigna los datos que nutren la historia de esta hierba; a diferencia del beleño, su símil europeo, la clasifica como una hierba caliente, ya que "excita y sube a la cabeza los vapores que producen sueño" (Hernández, 1959, Tomo II, p. 81), e identifica otra especie llamada quáuhyetl, "de florecilla más blanca, tallo más redondo, y hoja más lisa y más larga" (Hernández, 1959, Tomo II, p. 81). También menciona que a esta hierba se le conoce como tabaco, porque ese fue el nombre que le dieron los haitianos, aludiendo a "los sahumerios que también llaman tabacos" (Hernández, 1959, Tomo II, p. 81) y que se transmitió tanto a indios como españoles, mientras que otros como "nosotros" la llaman hierba sagrada o nicotina. El elogio al piciet/ se explica por el enorme repertorio de virtudes curativas y la versatilidad que presentan sus usos. En ese sentido, destaca la especificidad con la que el Protomédico da cuenta de ellos, haciendo hincapié en las maneras en que debe ser tratada la hierba según el tipo de enfermedad, como es el caso del humo que se obtiene de las hojas secas del picietl:

Envueltas en forma de tubo e introducidas en cañutos o en canales de papel, encendidas por un lado, aplicadas por el otro a la boca o a la nariz, y aspirando el humo con boca y nariz cerradas para que penetre el vapor hasta el pecho, provocan admirablemente la expectoración, alivian el asma por milagro, la respiración difícil y las molestias consiguientes (Hernández, 1959, Tomo II, p. 81).
El humo es eficaz también contra las afecciones de útero y las sofocaciones que suelen provenir de la subida de este; para fortalecer la cabeza, producir el sueño, calmar el dolor, para que el estómago recobre sus fuerzas, curar las jaquecas, y para engrosar "el sentido de las penas y trabajo e invade por completo el ánimo un reposo de todas las potencias (que podría casi llamarse embriaguez)" (Hernández, 1959, Tomo II, 81).

A este procedimiento o modo de tratar la hierba, Hernández se aproxima también desde el ámbito de las recetas. En ese sentido, hay que añadir las hojas verdes "marchitadas con las manos untadas en aceite" y luego "calentadas" que ayudan a la digestión y la cura del empacho, la reducción de las inflamaciones del bazo, los dolores provenientes del frío, la limpieza de heridas cancerosas y antiguas; el "jugo y polvo" de las hojas secas de la hierba, que ayudan a la cicatrización de algunas gotas, al igual que las heridas de la cabeza; las "hojas calentadas" para mitigar los dolores de dientes, "envolviendo con ellas la parte dolorida o introduciendo su masilla en los dientes huecos o agujereados" (Hernández, 1959, Tomo II, 82); el "polvo de las hojas aspirado" y tomado por la nariz para no sentir "los azotes o los suplicios de cualquier género, aumenta el vigor y fortalece el ánimo para sobrellevar los trabajos; "la corteza para el mal gálico; cura de modo admirable las heridas de flechas envenenadas, "Ilenando la herida de su polvo y dejándola así hasta que el polvo y el veneno se junten y coagulen en uno como clavo" (Hernández, 1959, Tomo II, 81), para calmar los dolores articulares y reducir las inflamaciones, quita la flatulencia y disipa dolores inveterados y rebeldes y, como si fuera poco, sirve como repelente para la molestia de las pulgas, "rociando la casa con el cocimiento de las hojas" (Hernández, 1959, Tomo II, 82).

Al final del capítulo, Hernández menciona un "medicamento" apetecido por los indios, del que están llenos los mercados y que hace eco de los manuscritos adscritos a la producción escrita del Colegio de Tlatelolco. Se trata de un compuesto elaborado a partir da la mezcla de "hojas secas y trituradas, en proporción de diez partes por una de cal" y que se vende envuelto en hojas de espiga de maíz,

y llevado entre la boca y las mejillas produce un suave sueño o un tranquilo reposo de los sentidos y de la mente, embota el sentido de toda las penas, y vuelve a los hombres prontos y ágiles para cualesquiera ejercicios corporales y principalmente para caminar; quita también los dolores de los dientes y de estómago, y presta otros servicios que, aunque no hayan sido dichos expresamente por nosotros, puede inferirse de todo lo anterior; son 
dignos de mención entre ellos que el aceite en que se haya frito después de dividirlo en pequeños trozos, cura introducido los cólicos, y que su jugo mexclado con el de huesos de tliltzápotl y con vino, introducido y aplicando luego al ano las hojas en forma de calilla, aleja las cuartanas y los fríos de todas las fiebres (Hernández, 1959, Tomo II, pp. 81-82).

La descripción da cuenta de un "medicamento" conocido, usado y demandado, cuyo propósito difiere de las virtudes que ofrecen las otras modalidades de uso, como las múltiples funciones del humo del picietl. No obstante, pese a la diferencia de su extensión, Hernández coincide con las escrituras previas. Al igual que el Libellus de medicinalibus y la Historia general de Sahagún, en la Historia natural de la Nueva España resuena la mezcla de la hierba con cal, la aplicación de las hojas molidas sobre el estómago, su ingesta en infusiones y las virtudes de fumarla, al igual que el cuidado que se debe tener frente a su condición "embriagante". Esta distinción opera como contorno para distinguir los límites virtuosos de la hierba, puesto que quienes la usan de auxilio con más frecuencia de la que conviene "se ponen descoloridos, con la lengua sucia y la garganta palpitante, sufren dolor al hígado, y mueren al fin atacados de caquexia e hidropesía" (Hernández, 1959, Tomo II, pp. $80-82)$.

\section{EL PICIETL EN LOS PRIMEROS IMPRESOS MÉDICOS NOVOHISPANOS}

La delimitación de las virtudes medicinales del picietl también conforman el sentido de las recetas entregadas por los impresos médicos y, en particular, las indicaciones sobre las maneras de preparar y aplicar el picietl dentro de los compuestos medicinales que conforman el "Antidotario de las drogas que van en este libro" en la segunda impresión del tratado médico de Alonso López de Hinojosos ${ }^{10}$. Cirujano romancista, López de Hinojosos desarrolló su oficio en los hospitales de Nuestra señora de la Concepción y también el de San José de los Naturales durante la segunda mitad del siglo XVI. Su experiencia en terreno lo llevó a publicar Suma y recopilación de cirujía en 1578, compuesta de siete tratados, cinco de ellos de predominio quirúrgico, y reimpreso con notorias modificaciones en 1595. Junto con la incorporación de un "Antidotario", el cirujano inscribió el saber de las hierbas medicinales locales gracias al contacto que tuvo con los curanderos indígenas que actuaban como ayudantes en el Hospital de Naturales, aunque también por las enseñanzas de Francisco Hernández, quien escogió este hospital y el de Oaxtepec para probar los efectos de las hierbas recogidas tras su expedición (Cordero Galindo, 1997; Martínez Hernández, 2014).
Al revisar las referencias al piciet/ dentro de su obra, Ilama la atención, tal como en el capítulo 28 del libro $X$ de la Historia general de las cosas de Nueva España, la ausencia de referencias al humo de las hojas secas con uso medicinal. La exclusión de esta práctica del antidotario puede rastrearse en otra sección de la obra elaborada con fines distintos: el libro VIII, que López tituló "sobre el cocoliztle" y que trata de la conmoción generada por la "pestilencia del cocoliztle" en 1576 y la propuesta de una comprensión médica a la epidemia ${ }^{11}$. En él, López nos cuenta que tras la autopsia realizada sobre un cadáver en Guaxaca en 1592, de quien "le dixeron que era gran chupador de humo de piciete", vio "que estaua su cuerpo como los que auia hecho anatomía; diez y seis años antes; cuando el gran cocoliste" (López, 1595, Lib. VIII, ffs.150v.-151r.). Se trataba de un cuerpo pestilente producto del humo "chupado", efecto de la astucia del demonio que "haziendole creer que mejor de sus enfermedades, y los engaña, porque siempre se andan ahogando, y amarillos" (López, 1595, Lib. VIII, f. 151r.). López hace alusión a las autopsias que llevó a cabo en el Hospital Real de Naturales en 1576, en presencia del Protomédico Francisco Hernández y el médico Juan de la Fuente, quien ocupó más tarde la primera cátedra de medicina en la Real Universidad de México. Su condición de testigo ocular le permitió asociar el "chupar el humo del piciete" con los males que generó en su momento la epidemia, negando la condición medicinal de esta práctica.

Para defender sus argumentos, López cita a Nicolás Monardes, médico Sevillano y autor de la Historia medicinal de las cosas que se traen de nuestras Indias Occidentales, en cuya segunda edición de 1571 ya había asociado el chupar el humo con los engaños del demonio, al referirse a las hojas que echaban en la lumbre los caciques cuando se les ofrecía algún negocio. Como ha planteado Sánchez Menchero, la obra de Monardes fue un caso temprano de diseminación del conocimiento del tabaco en el Viejo Mundo, responsable de perfilar las virtudes medicinales de la hierba en un primer ciclo de apropiación (2016, p.216). Según López, en el caso novohispano, el demonio les hace creer que al "chupar del humo" les hace mejorar, cuestión discutible desde el lenguaje médico, ya que el humo es un vapor y da "mal del coraçon, y a los que da muchas vezes los dexa simples, y necios" (López, 1595, Lib. VIII, f.151r.). Es más, el cirujano insiste a partir de una prueba llevada a cabo de manera contemporánea a la escritura del texto:

dire lo q me dixo vn estudiánte, q le dixo vno q chupase el humo: y se le oluido la licion que lleuaua bien sauida, y que en todo aquel dia no la pudo boluer a la memoria; para que vean los grandes daños que haze a los 
hombre, pues los haze tontos, e ynsipientes, y necios, sin firmeza ni constancia, y les anda hediendo la boca como a los borrachos del vino, y en dandoles alguna calentura; arden como fuego por estar secos los cuerpos, y sin humidad, y para remedia esto se mojan los cuerpos, y se reconcentran los humores abrasados del calor, se mueren sin cuydar ninguno estos daños, y otros muchos que por la honestidad no los digo, de lo que haze este humo del piciete. Si vemos q el humo tapa las héndeduras de las vigas, y de los encalados; quanto mas tapara el entendimiento este humo de piciete (López, 1595, Lib. VIII, ffs.151r. - 151v., énfasis mío).

De la cita anterior importa destacar la asociación empleada entre la condición de "tontos, e ynsipientes, y necios", y la hediondez del humo del picietl. El olvido como pérdida del entendimiento se manifiesta en estrecho vínculo con los criterios "higiénicos" que desbordan las fronteras simbólicas (Douglas, 2007) de la condición cristiana a la que deben optar los sujetos coloniales. Es una tensión que también se halla en los ambivalentes comentarios de Juan de Cárdenas en Problemas y secretos maravillosos de las Indias, impresa por Pedro Balli en 1591. A diferencia de López de Hinojosos, Cárdenas se formó en la Real Universidad de México y ensayó sus labores médicas en el Hospital de San Miguel de Guadalajara, el cual dependía de las autoridades catedralicias. Su obra, como el mismo lo expresa, se trata de una historia natural, aunque también dialoga con otras tipologías textuales, como la literatura de secretos y la problemata aristotélica. Sobre el piciet/ declara que:

cuando me pongo a imaginar quién aya sido el inventor de chupar este humo del piciete [...] sospecho que algún ángel le aconsejo a los indios o algún demonio; que sea ángel está puesto en razón, porque él nos libra de tantas enfermedades que verdaderamente parece medicina de ángeles; y que parezca ser remedio del demonio también lo está, porque si nos ponemos a mirar al que lo está chupando, lo veremos echar por la boca y narizes bocanadas de hidiondo humo, que parece un volcán o boca de infierno (Cárdenas, 1988, pp.195-196).

En ambos casos el problema de fondo no es el picietl en sí mismo, sino chupar de su humo como práctica medicinal. Arnold Bauer nos recuerda lo importante que son los modos en que son consumidos los bienes en una sociedad tejida a partir de la imposición de regímenes de bienes y mercancías. Con esto pone énfasis en la cuestión ideológica que cruza la preferencia de un bien en desmedro de otro, o qué y cómo debe ser consumido un medicamento, en la medida que estas elecciones habilitan o niegan la inscripción de los sujetos coloniales dentro de las expectativas del proyecto cristiano occidental. La clave es la noción de buena policía, una cate- goría que "suponía una serie de costumbres relacionadas con conceptos europeos de civilidad que incluían la ropa, la comida, la higiene"; por encima de todo, "vivir en policía significaba llevar una vida urbana" (Bauer, 2002 , p. 96). En otras palabras, una categoría que hace referencia a la forma cristiana en que debían vivir los sujetos, dentro de la lógica de "civilidad" anclada en el concepto de urbe (civitas), y donde el saber médico universitario y los oficios que operan bajo esa jerarquía cobraban sentido.

Dentro de este marco de expectativas, toman peso los comentarios de López de Hinojosos y Cárdenas sobre la hediondez del humo del picietl. Según David Le Breton, en la esfera sensorial de occidente, el olfato es un fuerte sentido de discriminación, ya que tiende a definir una alianza o ruptura, simpatía u odio. Esto se debe a la vinculación del olfato con la "intuición que va más allá de las apariencias visuales para captar indicios impalpables, que revelan una condición oculta, invisible para los demás" (2007, p. 230) y que cobra relevancia dentro de los imaginarios sociales que se tejen junto con estas demarcaciones. Elocuente es la connotación de rechazo y peligro que desarrollan los impresos, asociando el mal olor del humo con los efectos de dejar a las personas tontas y necias. Allí el olfato es "un marcador moral" (Le Breton, 2007, p. 237) que se nutre del imaginario demoniaco de lo sobrenatural, capaz de contribuir al desarrollo de prácticas poco urbanas (Muchembled, 2004).

En ese sentido, no es casual que los usuarios del humo del piciet/ señalados por Juan Bautista Pomar en su Relación de Texcoco (1582), sean "muy pocos de los indios que se crían entre españoles usan de ella, ni aun de la gente políticas y ciudadana, sino hombres rústicos y trabajadores" (López Austin, 1993, p. 139). Según Covarrubias, el término rústico remite al de villano, apelativo utilizado para referirse a los que viven en las villas "y como tienen poco trato con la gente de ciudad, son de su condición muy rusticos y desapacibles" (1611, Lib. II, f.74r.). Villano, a su vez, se vincula con otras condiciones, prácticas y actitudes; villano es el "que no sabe leer ni escribir" (Covarrubias, 1611, Lib. I, f. 367r.), "Llamamos salvaje al villano que sabe poco de cortesía" (Covarrubias, 1611, Lib. II, f. 20v.) y también vil: "puede traer origen del nombre villa, que vale aldea, y que sea vil lo mesmo que el villano, y dize más la baxeza de su persona, y de su condición y trato" (Covarrubias, 1611, Lib. II, f. 74r.). Como se expresa, connotaciones negativas e inherentes a los opuestos de la gente "política y ciudadana".

A su vez, los efectos del humo pueden ser peligrosos ya que pueden turbar el orden simbólico desple- 
gado por la urbe cristiana, de ahí que su integración sea negada o presente dificultades ${ }^{12}$. Ante el problema del "chupar del humo" del picietl, los textos toman opciones diferenciadas. López optó por marginarla de su clasificación medicinal; no se trata necesariamente del humo en sí mismo ${ }^{13}$, sino del humo del picietl. Por el contrario, son otros modos de usar el picietl que sí le resultan medicinales al cirujano, como el aceite del picietl, que sirve para los dolores del vientre y que se elabora con la hierba verde, seca y echándola en seis onzas de aceite común (López, 1595, f. 204r.). Por su parte, Cárdenas ensayó una forma "adecuada" para usar el humo del picietl. Advierte no usar la hierba si el enfermo padece de calenturas, ni en héticos y tampoco para quienes han arrancado sangre por cualquier parte de su cuerpo. Así mismo, propone un horario y modo de consumirlo: idealmente en las mañanas y en ayunas, si se toma a fin de preservar el hambre, o a la hora de la cena en pequeña cantidad cuando se hayan digerido los alimentos. Por seguridad, el médico recomienda usarlo envuelto en hoja de maíz y chuparlo sin tragarlo hasta el estómago, sino "sólo lo tienen en el paladar y campanilla", aunque si es para enfermedades frías del vientre y el estómago, es "mejor tragarle al estómago; el que sólo toma por la cabeza, basta echarlo por las narices y el que quisiere darle calor generalmente a todo su cuerpo y darle fuerça, puede [...] usarle de todas maneras" (Cárdenas, 1988, p.199).

El gesto estratégico de Juan de Cárdenas se inscribe en la lógica prescriptiva de los antidotarios y las indicaciones señaladas en el resto de los impresos, que sustentan los contornos del discurso del saber médico europeo. La especificidad de las cantidades, el modo y los horarios sugeridos permiten un ingreso regulado a la "materia médica". De tal forma, para fines del siglo, los textos tienden a focalizarse en otros usos del picietl: sus hojas marchitas y untadas con aceite, en aspirar por la nariz el polvo elaborado con sus hojas o también las virtudes de sus hojas cocidas para la preparación de distintos brebajes. En esa misma línea pueden leerse las referencias al piciet/ dentro del Tratado breve de medicina del médico Fray Agustín Farfán ${ }^{14}$. Indicaciones como "del piciete, pueden tomar vn dia o dos" (Farfán, 1610, Lib. II, f.71), "quatro hojas (de lo que Ilaman piciete)" (Farfán, 1610, Lib. III, f. 195v.); "tanto piciete molido ò tabaco como vna Nuez" (Farfán, 1610, Lib. II, f. 142r.); "vn poco de Piciete o Tauaco molido" (Farfán, 1610, Lib. II, f. 156v.) son elocuentes al respecto.

\section{CONCLUSIÓN}

Como hemos visto, el ingreso del piciet/ a los marcos de la "materia médica" significó un delineamiento sobre qué partes o usos de la hierba podrían inscribirse dentro del discurso médico. En ese sentido, el registro y clasificación de lo "medicinal" supuso no solo representar bajo los cánones disponibles, sino también delimitar y jerarquizar las formas en que los sujetos cristianos podían establecer un vínculo con las materias naturales. Por ese motivo, la clasificación del picietl se inscribe en un horizonte más amplio, en el de los esfuerzos de la medicina cristiana por hegemonizar la comprensión de la salud y la enfermedad en todos los confines del imperio hispano. Mientras en América los médicos europeos enfrentan la "idolatría" de los indios mexicanos, cuyas prácticas incorporan el uso de hierbas, plantas y raíces, en el Viejo Mundo la medicina universitaria enfrentan el pluralismo de las prácticas médicas y las "supersticiones" del vulgo. En la medida que los saberes reconocidos como "profesionales" convivían con ejercicios y procedimientos clasificados como "sobrenaturales" y "mágicos", las prácticas populares ponían en tensión los modos de comprensión de la salud -e incluso la "naturaleza"- que eran propios del canon universitario (Campagne, 2002, pp. 421-423).

Los intentos por delimitar los contornos "medicinales" del piciet/ se comprenden en ese esfuerzo por jerarquizar la "naturaleza" de América, distinguiendo lo que les es propio a dicho dominio. Si bien la tendencia fue la omisión o regulación del humo del picietl, tan explícita en los impresos médicos, a diferencia de la declarada aceptación de esta práctica en obras como las de Sahagún o Hernández, lo que queda de manifiesto es la condición profundamente heterogénea y dispar del proceso de invención del picietl como parte de la materia médica novohispana. Recordemos que todos estos esfuerzos fueron contemporáneos y que cada obra negoció, a su manera, los preceptos y prejuicios del saber médico europeo y la "naturaleza" de América, comunicada y transferida en modalidades particulares por medio de la presencia, a veces oculta o silenciada, de los "médicos indígenas". Se trata de un proceso clasificatorio poblado de fisuras, cuestión que pone en evidencia que los valores y énfasis sobre los usos de las hierbas, tan determinantes en su codificación medicinal, no fueron compartidos del todo. En ese sentido, conviene matizar la premisa de Descola sobre la "cosmología naturalista" que caracterizaría al occidente moderno, e invitar a profundizar en la heterogeneidad de formas en que las medicinas y el territorio americano emergen bajo el léxico del saber médico de los colonizadores, responsable de traducir, a su universo cognitivo, la "naturaleza" antes inexistente del Nuevo Mundo. 


\section{NOTAS AL FINAL}

1 Bajo este esquema, los humores servían a distintos propósitos. La sangre era la fuente de la vitalidad, la bilis era el jugo gástrico, indispensable para la digestión; la flema, lubricante y refrigerante, comprendía todas las secreciones incoloras, visible también en el sudor y las lágrimas; la bilis negra, o melancolía, era más problemática porque nunca se encontraba en estado puro, no obstante, se le consideraba el "responsable de oscurecer otros fluidos, como cuando la sangre, la piel o las heces se volvían nauseabundas" (Porter, 2004, p. 59).

2 Si dudan, la propuesta de Reynolds, van der Geest y Hardon se nutre de la categoría de regímenes de valor propuesta por el antropólogo Arjun Appadurai en su estudio sobre la relación entre cultura y mercancías. Según el autor, regímenes de valor alude a las esferas de circulación que otorga valor a un objeto, de acuerdo con contextos históricos y estructuras de significación específicas, pero que no necesariamente son compartidas por todos, ni tampoco los intereses de quienes comparten un mismo régimen de valor. Puesto que se trata del "marco cultural" (Appadurai, 1991, p. 30), esta propuesta sirve para pensar los modos en que los agentes hispanos otorgan valor "medicinal" a las hierbas de Nueva España mediante la representación y la prescripción de la materia médica local y su vinculación con los modos de comprensión cristiano occidentales.

3 En cuanto a su contenido, el herbario se divide en 13 capítulos, cada uno relacionado con las enfermedades de una parte específica del cuerpo, desde la cabeza hacia abajo. Cada enfermedad y tratamiento respectivo se halla escrito en latín, con excepción de los nombres de las hierbas locales, escritos en náhuatl, condición que también corre para los 184 dibujos de hierbas.

4 Sahagún se había formado en la Universidad de Salamanca, en un ambiente humanista, lo que le llevó a flexibilizar los modelos de las autoridades escolásticas. Como lo expresa en el prólogo del libro II, el fraile organizó la información que les proporcionaron durante años los sabios indígenas o "informantes" gracias a la colaboración de los indios "gramáticos", que habían sido formados por él mismo, y un cuestionario que ensayó por vez primera en Tepepulco entre 1558 y 1559 , donde obtuvo un documento en náhuatl que se ha denominado Primeros memoriales y que usó después para el desarrollo de un cuestionario más extenso. Una segunda etapa de esta obra se desarrolló en Tlatelolco, editando el manuscrito y elaborando lo que se conoce como Códice Matritense, también escrito en náhuatl. La última etapa de recopilación es cuando Sahagún se trasladó al convento de San Francisco de Ciudad de México en 1565, donde la obra volvió a revisarse y editarse, siendo ilustrada y traducida al español, convirtiéndose así en el mencionado Códice Florentino.

5 Tomo la expresión propuesta por José Luis Martínez para referirme en conjunto al vocabulario en náhuatl de vocablos en relación con el cuerpo humano que constituyen el capítulo XVII del libro X, titulado "De todos los exteriores e interiores así en el hombre como en la mujer", el segmento del capítulo XVIII “De las enfermedades del cuerpo humano y las medicinas contra ellas" y el inventario de hierbas medicinales que forma parte del libro XI de historia natural.

6 Sahagún, Lib. X, cap. 28, f. 98r.

7 Sahagún, Lib. X, cap. 28, f. 98r.

8 Sahagún, Lib. X, cap. 28, f. 100v.

9 Sahagún, Lib. X, cap. 28 f. $103 v$

10 Al igual que otras hierbas locales, el picietel se difumina en las mezclas con otras sustancias para la elaboración de distintos remedios: cocido y mezclado con çapote colorado y polvos de chile colorado para sanar jaquecas (López, 1595, f. 191r.); en forma de zumo para el ungüento desopilativo (López de Hinojosos, 1595, f. 192v.); vino para sanar rotura (López,1595, f. 198r.); hojas del picietel con anís para sanar fríos y calenturas (López de Hinojosos, 1595, f. 200r.) junto con el çapote, aceite y miel para el dolor de vientre, hijada, riñones y de ciática (López de Hinojosos, 1595, f. 201v.); polvos de piciete y de safetán, o también hojas de piciete molidas con almendras de çapote colorado para los que no pueden orinar (López de Hinojosos, 1595, f. 213v.).

11 De igual forma, Hernández ensayó una explicación médica en su manuscrito "De la enfermedad de la Nueva España del año 1576 llamada por los indios cocoliztli". En: Hernández, Francisco, Obras Completas. Tomo VI. Escritos Varios, México, UNAM, pp. $474-482$.

12 Desde fines del siglo XVI el debate sobre el humo del tabaco cobró mayor relevancia, tanto en territorio americano como en los centros metropolitanos. El Diálogo del uso del tabaco de Bartolomé Marradón, impreso en Sevilla en 1618, y la Historia de las virtudes y propiedades del Tabaco y de los modos de tomarle para las partes intrínsecas y de aplicarles a las extrínsecas, impreso en Córdoba en 1625 , son algunos ejemplos de este debate nutrido por la difusión y generación de un conocimiento médico diseminado en medio de la producción impresa.

13 El mismo "Antidotario" recomienda hacer un sahumerio para curar el dolor de cabeza, aunque con copal, incienso, aceite de abeto o liquidámbar, bermellón molido para hacer pastillas “y con estas se sahume” (López, 1595, f. 195r.).

14 Hago alusión a la segunda edición de la obra del médico Agustín Farfán, originalmente impresa en 1579, la que llevaba por título Tratacdo breve de anaothomía y cirugía. Como ha señalado Pardo-Tomás (2017), la segunda edición es diferente, pues solo coincide en la exposición sobre anatomía que, en vez de ir en un principio, se dejó para el final. Por el contrario, esta edición incrementa la exposición de enfermedades y también los remedios, entre los que se integran un significativo número de hierbas medicinales locales, que no se presentan en la edición de 1579 . Es este mismo volumen el que se vuelve a imprimir en 1610 sin cambios significativos y que utilizo como referencia. 


\section{MATERIALES}

Cárdenas, Juan de (1988) [1591], Problemas y secretos maravillosos de las Indias, México, Alianza Editorial.

Covarrubias, Sebastián de (1611),Tesoro De La Lengua Castellana, O Española. Compvesto por el licenciado Don Sebastian de Cobarruuias Orozco, Capellan de su Magestad, Mastescuela y Canonigo de la Santa Yglesia de Cuenca, y Consultor del Santo Oficio de la Inquisición. Dirigido a la Magestad Catolica del Rey Don Felipe III, nuestro señor, Madrid: por Luis Sánchez, impresor del Rey.

De la Cruz, Martín (1996), Libellus De Medicinalibus Indorum Herbis. Manuscrito Azteca de 1552. Según traducción latina de Juan Badiano, México, Fondo de Cultura Económica - Instituto Mexicano del Seguro Social.

Farfán, Agustín (1610) [1579, 1592], Tratado Breve De Medicina Y De Todas Las Enfermedades, hecho por el Padre Fray Agustin Farfan, Doctor en Medicina, Religioso indigno de la Orden de San Agustin, en la Nueua España. Agora nueauemente añadido, México, Imprenta de Geronymo Balli, por Cornelio Cesar.

Hernández, Francisco (2015) [1570 - 1577], Obras Completas. 7 tomos, México, Universidad Nacional Autónoma de México.

López de Hinojosos, Alonso (1595) [1578]., Summa y Recopilación de Cirvgia, Con Vn Arte Para Sangrar, y examen de barberos, compvesto por maestre Alonso Lopez de Hinojoso. Va añadido en esta segvnda impresion el origen y Nascimiento de las reumas, y las enfermedades que dellas proceden, con otras cosas muy prouechosas para acudir al remedio dellas, $y$ de otras muchas enfermedades, México, Impreso por Pedro Balli.

Monardes, Nicolás (1574) [1569], Primera y Segunda y Tercera partes de la Historia Medicinal de las cosas que traen de nuestras Indias Occidentales que sirven en Medcina, Sevilla, impreso en casa de Alonso Escrivano.

Sahagún, Bernardino de (1577), "Historia general de las cosas de Nueva España: el Códice Florentino", [en línea], dispomible en: https://www.wdl.org/en/item/10096/view/1/5/, consultado el 22/03/2020].

\section{BIBLIOGRAFÍA}

Anderson, Frank J. (1997), An Illustrated History of the Herbals, New York, Columbia University Press.

Appadurai, Arjun (1991), “Introducción: las mercancías y la política del valor". En: Appadurai, Arjun (ed.), La Vida Social De Las Cosas. Perspectivas culturales de la mercancía, México, Grijalbo, pp. 17-88.

Barrera Osorio, Antonio (2009), "Knowledge and Empiricismo in the Sixteenth-Century Spanish Atlantic World". En: Bleichmar, Daniela; De Vos, Paula; Huffine, Kristin; Sheehan, Kevin (eds.), Science in the Spanish and Portuguese Empires, 15001800, California, Stanford University Press, pp. 219 - 232.

Bauer, Arnold J. (2002), Somos Lo Que Compramos. Historia de la cultura material en América Latina, México, Taurus.
Bleichmar, Daniela; De Vos, Paula; Huffine, Kristin; Sheehan, Kevin (eds.) (2009), Science in the Spanish and Portuguese Empires, 1500-1800, California, Stanford University Press.

Burke, Peter (2002), Historia social del conocimiento. De Gutenberg a Diderot, Buenos Aires, Paidós.

Campagne, Fabían Alejandro (2002), Homo Catholicus. Homo Superstitiosus. El discurso antisupersticioso en la España de los siglos X a XVIII, Madrid, Universidad de Buenos AiresMiño y Dávila editores.

Cañizares-Esguerra, (2006), Nature, Empire, and Nation: Explorations of the History of Science in the Iberian New World, California, Stanford University Press.

Cordero Galindo, Ernesto (1997), “Alonso López de Hinojosos, el primer cirujano novohispano. Estudio comparativo de su obra", Boletín II (1), pp. 41- 64.

Descola, Philippe (2012), Más allá de naturaleza y cultura, Buenos Aires, Amorrortu.

Douglas, Mary (2007), Pureza Y Peligro. Un análisis de los conceptos de contaminación y tabú, Buenos Aires, Ediciones Nueva Visión.

Foucault, Michel (2008), Las palabras y las cosas, Buenos Aires, Siglo XXI.

Fresquet, José Luis; López Piñero, José María (eds.) (1995), E Mestizaje Cultural y la Medicina Novohispana del Siglo XVI, Valencia, Instituto de Estudios Documentales E Históricos Sobre a Ciencia Universitat de Valencia- C.S.I.C.

Gerbi, Antonello (1978), La naturaleza de las Indias Nuevas, México, Fondo de Cultura Económica.

Glacken, Clarence J. (1996), Huellas en la playa de Rodas. Naturaleza y cultura en el pensamiento occidental desde la Antigüedad hasta finales del siglo XVIII, España, Ediciones del Serbal.

Goodman, David (2009), "Science, Medicine, and Technology in Colonial Spanish America: New Interpretations, New Approaches". En: Bleichmar, Daniela; De Vos, Paula; Huffine, Kristin; Sheehan, Kevin (eds.), Science in the Spanish and Portuguese Empires, 1500-1800, California, Stanford University Press, pp. 9-34.

Gruzinski, Serge (2015), Las cuatro partes del mundo. Historia de una mundialización, México, Fondo de Cultura Económica.

Laird, Andrew (2014), "Nahuas and Caesars: classical learning and bilingualism in Post-Conquest Mexico: an invertory of latin writings by authors of the native nobility", Classical Philology 109 (2), pp. 150-169.

Le Breton, David (2007), El sabor del mundo: una antropología de los sentidos, Buenos Aires, Ediciones Nueva Visión.

Le Goff, Jacques (1990), Los intelectuales en la Edad Media, Barcelona, Gedisa.

López Austin, Alfredo (1971), "De las plantas medicinales y de otras cosas medicinales". Estudios de cultura náhuatl 9, pp. $125-230$.

López Austin, Alfredo (1993), Textos de medicina náhuatl, México, UNAM - Instituto de Investigaciones Históricas. 
Martínez Hernández, Gerardo (2014), La medicina en la Nueva España, siglos XVI y XVII. Consolidación de los modelos institucionales y académicos, México, UNAM.

Martínez, José Luis (1981), “Prólogo”. En: José Luis (ed.), El México Antiguo, Venezuela: Ed. Ayacucho, pp. IX-CII.

Marroquín Arredondo, Jaime; Bauer, Ralph (2019), "Introduction: An Age of Translation". En: Translating Nature. Cross-Cultural Histories of Early Modern Science, Philadelphia, University of Pennsylvania Press, pp. 1-13.

Morales Sarabia, Angélica (2014), "Tres caminos posibles: una ausencia, una marca tipográfica y un evento fortuito. El peyote y otras hierbas en la materia médica (siglos XVI-XVII)". En: Pardo-Tomás, José; Sánchez Menchero, Mauricio (eds.), Geografías médicas. Orillas y fronteras culturales de la medicina novohispana (siglos XVI y XVII), México, CEIICH, UNAM, pp. 47-74.

Muchembled, Robert (2004), Historia Del Diablo. Siglos XII-XX, México, Fondo de Cultura Económica.

Navarrete, Federico (2002), "La sociedad indígena en la obra de Sahagún”. En: León-Portilla, Miguel (ed.), Bernardino de Sahagún. Quinientos años de presencia, México, UNAM- Instituto de Investigaciones Históricas, pp. 97- 116.

Navarrete, Federico (2016), "Las historias de América y las historias del mundo: una propuesta de cosmohistoria", AJEL 36, pp. 1-35.

Nieto, Mauricio (2009), “Ciencia, imperio, modernidad y eurocentrismo: el mundo atlántico del siglo XVI y la comprensión del Nuevo Mundo", Historia Crítica 39, pp. 12-32.

O’ Gorman, Edmundo (2003), La invención de América, México, Fondo de Cultura Económica.

Pardo-Tomás, José; Sánchez Menchero, Mauricio (eds.) (2014), Geografías médicas. Orillas y fronteras culturales de la medicina novohispana (siglos XVI y XVII), México, CEIICH, UNAM, p. 9.
Pardo-Tomás, José; López Terrada, María Luz (1993), Las primeras noticias sobre plantas americanas en las relaciones de viajes y crónicas de Indias (1493 - 1553), Valencia, C.S.I.C.

Pardo-Tomás, José (2002), El tesoro natural de América. Colonialismo y ciencia en el siglo XVI: Oviedo, Monardes, Hernández, Madrid, Nivola.

Pardo-Tomás, José (2017), ““Y los remedios serán los más caseros": el arsenal terapéutico mesoamericano en la obra de fray Agustín Farfán: entre la desconfianza y la expropiación". En: Morales Sarabia, Angélica, José Pardo-Tomás y Mauricio Sánchez Menchero (coord.). De La Circulación Del Conocimiento A La Inducción De La Ignorancia. Culturas médicas trasatlánticas, siglos XVI y XVII, México, Universidad Nacional Autónoma de México- CEIICH, pp. 17-47.

Porter, Roy (2004), Breve historia de la medicina. Las personas, la enfermedad y la atención sanitaria, México, Taurus.

Rappaport, Joanne; Cummins, Tom (2012), Beyond The Lettered City. Indigenous literacies in the Andes, Durham and London, Duke University Press.

Raynolds Whyte, Susan; Sjaak van der Geest y Anita Hardon (2002). "An anthropology of materia medica". En: Raynolds Whyte, Susan; Sjaak van der Geest y Anita Hardon (eds.) Social Lives of Medicines, United Kingdom, Cambridge University Press, pp. 3- 22

Siraisi, Nancy G. (1990), Medieval \& Early Renaissance Medicine An Introduction to Knowledge and Practice, Chicago and London: The University of Chicago Press, 1990.

Trabulse, Elías (1992), Historia de la ciencia en México. Estudios y textos, Siglo XVI, México, Conacyt - Fondo de Cultura Económica.

Viveiros de Castro, Eduardo (2010), Metafísicas caníbales. Líneas de antropología posestructural, Buenos Aires, Katz Editores. 